\title{
Heat Transfer in Rotating Serpentine Passages With Trips Skewed to the Flow
}

B.V. Johnson and J.H. Wagner

United Technologies Research Center

East Hartford, Connecticut

G.D. Steuber

Pratt \& Whitney

East Hartford, Connecticut

and

F.C. Yeh

Lewis Research Center

Cleveland, Ohio

Prepared for the 37th American Society of Mechanical Engineers International Gas Turbine and Aeroengine Congress and Exposition sponsored by the 1992 ASME Turbo Expo-Land, Sea and Air Cologne, Germany, June 1-4, 1992

\section{N/Sก}




\section{HEAT TRANSFER IN ROTATING SERPENTINE PASSAGES WITH TRIPS SKEWED TO THE FLOW}

\author{
B. V. Johnson \\ J. H. Wagner \\ United Technologies Research Center \\ East Hartford, CT 06108
}

\author{
G. D. Steuber \\ Pratt \& Whitney \\ East Hartford, CT 06108
}

\author{
F. C. Yeh \\ Lewis Research Center \\ Cleveland, $\mathrm{OH} 44135$
}

\begin{abstract}
Experiments were conducted to determine the effects of buoyancy and Coriolis forces on heat transfer in turbine blade internal coolant passages. The experiments were conducted with a large scale, multi-pass, heat transfer model with both radially inward and outward flow. Trip strips, skewed at 45 degrees to the flow direction, were machined on the leading and trailing surfaces of the radial coolant passages. An analysis of the governing flow equations showed that four parameters influence the heat transfer in rotating passages: coolant-to-ivall temperature ratio, rotation number. Reynolds number and radius-to-passage hydraulic diameter ratio. The first three of these four parameters were varied over ranges which are typical of advanced gas turbine engine operating conditions. Results were correlated and compared to previous results from similar stationary and rotating models with smooth walls and with trip strips normal to the flow direction. The heat transfer coefficients on surfaces, where the heat transfer decreased with rotation and hunyancy, decreased to as low as 40 percent of the value without rotation. However, the maximum values of the heat transfer coefficients with high rotation were only slightly above the highest levels previously obtained with the smooth wall model. It was concluded that (1) both Coriolis and buoyancy effects must be considered in turbine blade cooling designs with trip strips. (2) the effects of rotation are markedly different depending upon the flow direction and (3) the heat transfer with skewed trip strips is less sensitivity to buoyancy than the heat transfer in models with either smooth walls or normal trips. Therefore, skewed trip strips rather than normal trip strips are recommended and geometry-specific tests will be required for accurate design information.
\end{abstract}

\section{NOMENCLATURE}

A Area of passage cross-section

d Hydraulic dianeter

e Trip height

Gr Rotational Grashof number

h Heat transfer coefficient

J Rotational Reynolds number

$k$ Thermal conductivity

m Mass flowrate

Nu Nusselt number, hd/k

$\begin{array}{ll}\mathrm{P} & \text { Trip spacing, i.e. pitch } \\ \mathrm{R} & \text { Local radius } \\ \mathrm{Re} & \text { Reynolds number, }(\mathrm{md}) /(\mu \mathrm{A}) \\ \mathrm{Ro} & \text { Rotation number, } \Omega \mathrm{d} / \mathrm{V} \\ \mathrm{T} & \text { Temperature } \\ \mathrm{V} & \text { Mean coolant velocity } \\ \mathrm{X} & \text { Streamwise distance from inlet } \\ \mu & \text { Absolute viscosity } \\ \nu & \text { Kinematic viscosity } \\ \rho & \text { Coolant density } \\ \Delta \rho / \rho & \text { Density ratio, }\left(\rho_{\mathrm{w}}-\rho_{\mathrm{w}}\right) / \rho_{\mathrm{l}} \\ \Omega & \text { Rotational speed }\end{array}$

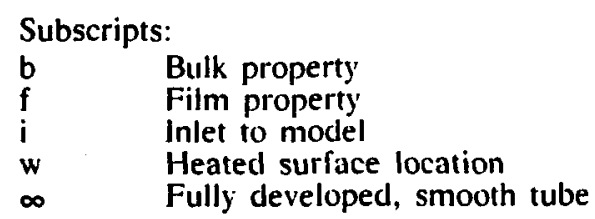

\section{Superscripts: \\ - Average \\ , Distance from beginning of second passage \\ " Distance from beginning of third passage}

\section{INTRODUCTION}

Advanced gas turbine airfoils are subjected to high heat loads that require escalating cooling requirements to satisfy airfoil life goals. The efficient management of cooling air dictates detailed knowledge of local heat load and cooling air flow distribution for temperature and life predictions. However, predictions of heat transfer and pressure loss in airfoil coolant passages currently rely primarily on correlations derived from the results of stationary experiments. Adjustment factors are usually applied to these correlations to bring them into nominal correspondence with engine experience. This is unsatisfactory when blade cooling conditions for new designs lie outsicle the range of previous experience.

Rotation of turbine blacie cooling passages gives rise to Coriolis and buoyancy forces which can significantly alter the local heat transfer in the internal coolant passages due to the 
development of cross stream (Coriolis) as well as radial (buoyant) secondary flows. Buoyancy forces in gas turbine blades are substantial because of the high rotational speeds and coolant temperature gradients. Earlier investigations (Eckert et al., 1953) with stationary, single pass, co- and counter-flowing coolant passages indicated that there can also be substantial differences in the heat transfer when the buoyancy forces are aligned with or counter to the forced convection direction. A better understanding of Coriolis and buoyancy effects and the capability to predict the heat transfer response to these effects will allow the turbine blade designer to achieve cooling configurations which utilize less flow and which reduce thernal stresses in the airfoil.

An extensive analytical and experimental program was originated and sponsored by NASA at the Lewis Research Center as part of the Hot Section Technology (HOST) program. The objectives of this progran were (1) to gain insight regarding the effect of rotation on heat transfer in turbine blade passages, (2) to develop a broad data base for heat transfer and pressure drop in rotating coolant passages, and (3) to improve computational techniques and develop correlations that can be useful to the gas turbine industry for turbine blade design. The attainment of these nhjectives became even more critical with the advent of the Integrated High Performance Turbine Engine Technology (IHPTET) initiative. As part of the IHPTET goal, the turbine would operate at near stoichiometric, i.e., 2200-2500 K, $(3500-4000 \mathrm{~F})$ inlet temperatures, maintain efficiencies in the $88-94 \%$ range, and require total coolant flows of only $5 \%$ of the engine air flow rate (Ref. IHPTET Brochure, Circa 1984). To attain these ambitious goals, a thorough understanding of the rotational effects of heat transfer and flow in turbine blade coolant passages is mandatory.

\section{Previous Studies}

Heat transfer experiments in multiple-pass coolant passages with skewed trips have been conducted in stationary models by several investigators to obtain a data base for the thermal clesign of gas turbine airfoils, e.g. Boyle (1984), Han et al. (1986). Metzger et al. (1988). These data bases are directly applicable to the cooling designs of stationary vanes. However, the effects of Coriolis forces and buoyancy, due to the large rotational gravity forces (up to $50,000 \mathrm{~g}$ ), are not accounted for.

The complex coupling of the Coriolis and buoyancy forces has prompted many investigators to study the flow field generated in unheated, rotating circular and rectangular smooth wall passages without the added complexity of buoyancy, i.e., Moore (1967), Hart (1971). Wagner and Velkoff (1972), and Johnston et al. (1972). These investigators have documented strong secondary flows and have identified aspects of flow stability which produce streamwise oriented, vortex-like structures in the flow of rotating radial passages. The effects of rotation on the location of flow reattachment after a backward facing step was presented by Rothe and Johnston (1979). This work was especially helpful in understanding the effects of rotation on heat transfer in passages with normal trips. However, the secondary flow patterns associated with skewed trips and Coriolis forces can produce additional complex interactions.

The combined effects of Coriolis and buoyancy forces on heat transfer have been studied by a number of investigators during the past twenty years. Heat transfer experiments in rotating models with smooth walls has been reported by Wagner et al. (1991a, and 1991b), Guidez (1989). Iskakov and Trushin (1983), Morris (1981), Morris and Ayhan (1979), Lokai and Gunchenko (1979), Johnson (1978), and Mori et al. (1971). Heat transfer experiments in rotating models with normal trips have been reported by Wagner et al. (1991c) and Taslim et al. (1991a). Heat transfer in a rotating model with criss-cross skewed trips was recently reported by Taslim et al. (1991b). Large increases and decreases in local heat transfer from smooth walls or walls with trips were found by some investigators uncler certain conditions of rotation while other investigators showed lesser effects. Analysis of these results does not show consistent trends. The inconsistency of the previous results is attributed to differences in the measurement techniques, models and test conditions.

\section{Objectives}

Under the NASA HOST program, a comprehensive experimental project was formulated to identify and separate effects of Coriolis and buoyancy forces for the range of dimensionless flow parameters encountered in axial flow, aircraft gas turbines. The specific objective of this experimental project was to acquire and correlate benchmark-quality heat transfer data for a multi-pass, coolant passage under conditions similar to those experienced in the blades of advanced aircraft gas turbines. A comprehensive test matrix was formulated, encompassing the range of Reynolds numbers, rotation numbers, and density ratios expected in modern gas turbine engines.

The results presented in this paper are from the third phase of a three phase program directed at studying the effects of rotation on a multi-pass model with smooth and rough wall configurations. The first phase utilized the smooth wall configuration. Initial results for outward flow in the first passage were previously presented by Wagner, et al. (1991a). The effects of flow direction and buoyancy with smooth walls were presented by Wagner, et al. (199/b). The second phase utilized a configuration with normal trips on the leading and trailing surfaces of the straight passages and were presented by Wagner, et al. (1991c). The heat transfer results with normal trips showed that large decreases in heat transfer could occur on certain surfaces due to rotation and that the heat transfer coefficients could also have a large sensitivity to buoyancy. The present paper covers the phase with surface roughness elements oriented at 45 degrees to the flow direction. Comparisons will be made with the results for smooth walls and the walls with normal trips in the same model and with concurrent rotating and stationary experiments employing trips skewed to the flow direction.

The results from the present work will show that large decreases in heat transfer coefficients can occur clue to rotation. However, the heat transfer coefficients for the model with skewed trips show much less sensitivity to buoyancy than the results from the models with either smooth walls or normal trips. Physical models to account for these heat transfer characteristics will be proposed in the discussion herein.

The facility, data acquisition and data reduction technicpues employed in this experiment were discussed in the Wagner et al. (1991a) paper and will not be repeated. However. the description of the model will be repeated for the convenience of the reader.

\section{DESCRIPTION OF EXPERIMENTAL EQUIPNIENT}

\section{Heat Transfer Model}

The heat transfer model was designed to simulate the internal multi-passage geometry of a cooled turbine blade (Figure 1). The model consists of three straight sections and three turn sections which were instrumented followed by one uninstrumented straight section, as shown in Figure 2 . The model orientation with respect to the rotational centerline for $\alpha=$ 45 deg are shown in Figure $3 \mathrm{~b}$. Data presented herein were obtained in the first, second and third passages with radially outward, inward and outward flow. respectively. The model passages are approximately square with a characteristic dimension of $12.7 \mathrm{~mm}$ (0.5 in.). Four elements form the walls of the square coolant passage at each streamwise location. The heated length of the first passage is 14 hydraulic diameters and is comprised of sixteen heated copper elements at four streamwise locations. The heated copper elements at the first streamwise location were all smooth walls and were used as guard heaters. 


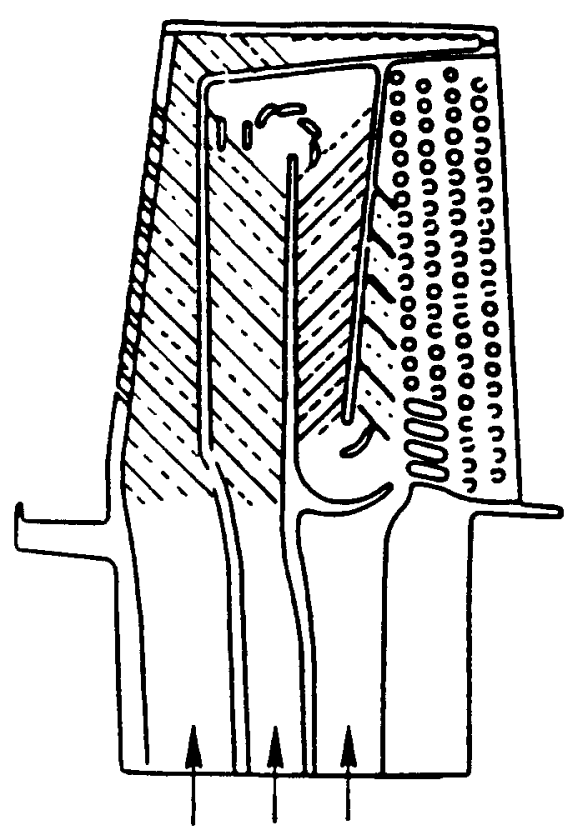

Fig. 1 Typical Coolant Passage Configuration for Aircrat Gas Turbine Rotating Airfoils.

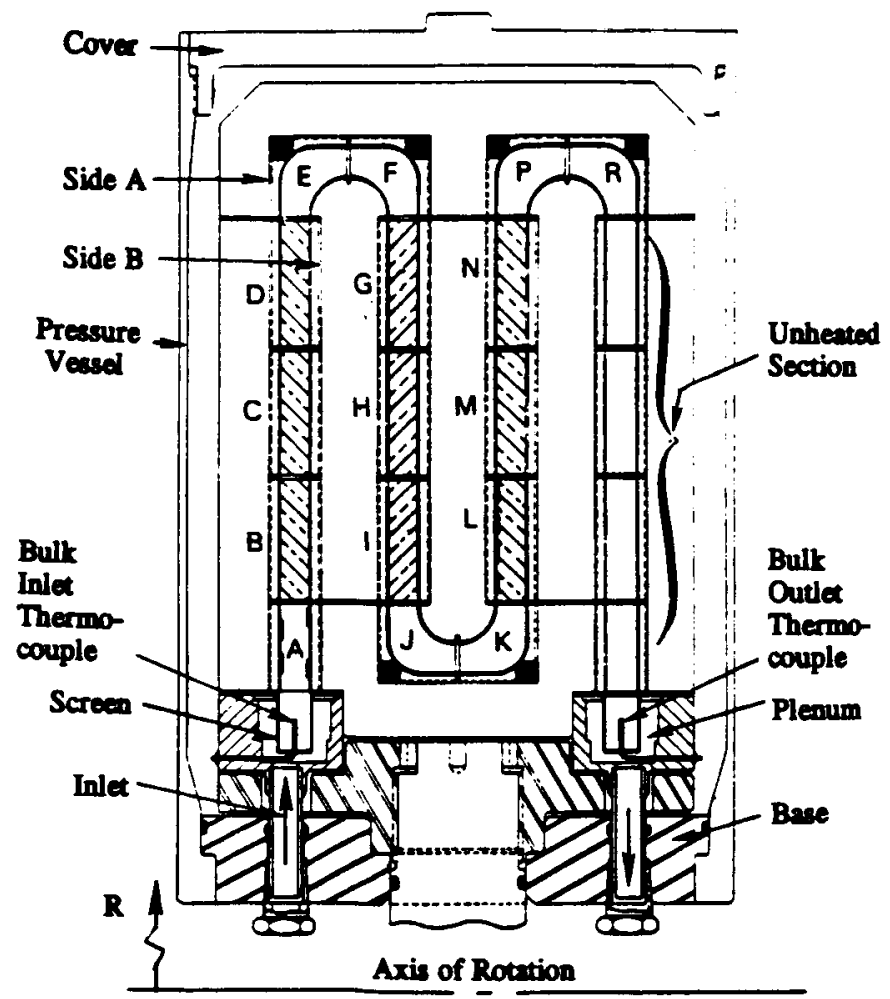

Fig. 2 Cross Sectional View of Coolant Passage Heat Transfer Model Assembly With Skewed Trip Rough Walls; view through center of model toward leading surfaces with $\Omega>0$, dotted ribs show locations on the trailing surfaces.

The cross-section views of Figures 2 and 3 show the orientation of the leading, trailing and sidewall surfaces. The

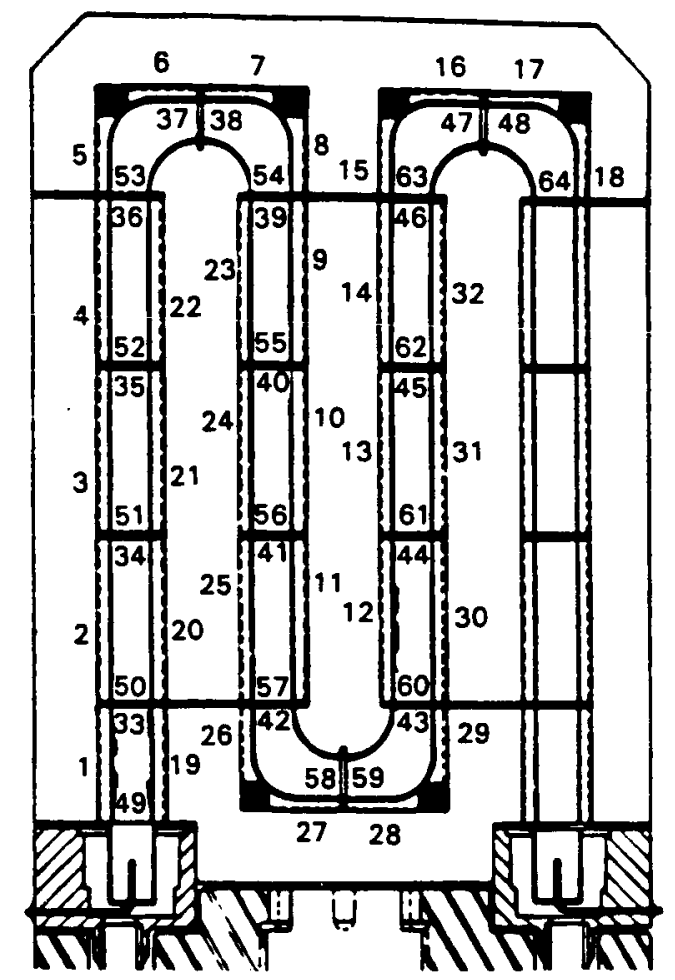

Fig. 3a Cross Sectional View of Test Surface Identification Plan for Coolant Passage Heat Transfer; side wall test section surfaces 1-32 are in plane perpendicular to view shown, test section surfaces $33-48$ are on " $+\Omega$ " leading plane, test section surfaces $49-64$ are on " $+\Omega$ " trailing plane.

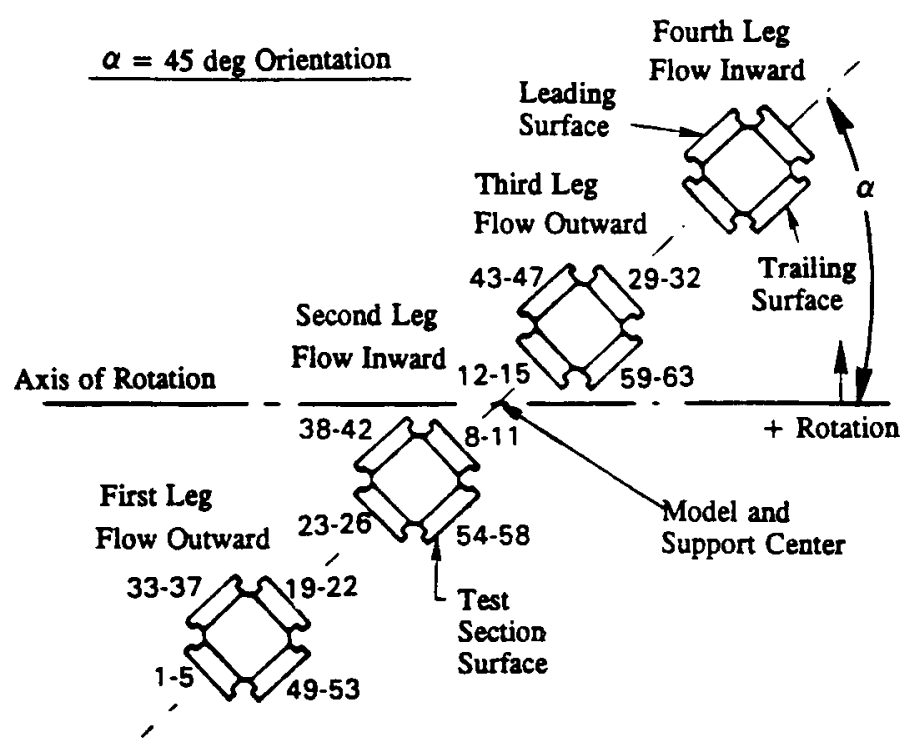

Fig. 3b Test Surface Identification Plan for Coolant Passage Heat Transfer; view from outer turn sections.

streamwise locations, A through $\mathrm{R}$, are shown in Figure 2 . The test surface identification plan for each heated surface is shown in Figures $3 a$ and $b$. Each copper element is heated on the side opposite the test surface with a thin film, $0.1 \mathrm{~mm}(0.003 \mathrm{in}$.), resistance heater. Each element is $3.8 \mathrm{~mm}(0.150$ in.) thick and is thermally isolated from surrounding elements by $1.5 \mathrm{~mm}$ $(0.060$ in.) thick fiberglass insulators. The insulating material 
separating the copper elements at each streamwise location resulted in a $1.0 \mathrm{~mm}(0.04$ in.) chamfer in the corners, which yielded a hydraulic diameter, $d$, in the straight sections of 13.2 $\mathrm{mm}(0.518 \mathrm{in}$.). The radius at the center of the heat transfer test sections with trips, i.e., average model radius, was $663 \mathrm{~mm}(26.1$ in.). The power to each element was adjusted to obtain an isothermal wall boundary condition. In practice, temperature differences less than $1 \mathrm{C}(2 \mathrm{~F})$ were achieved. The heat flux between elements with a $1 \mathrm{C}(2 \mathrm{~F})$ temperature difference was estimated to be less than 2 percent of a typical stationary surface-to-coolant heat flux.

Trip strips were machined in a staggered pattern on the leading and trailing surfaces of the $152.4 \mathrm{~mm}$ (6 in.) straight length of each passage as shown in Figure 2. No trips were on the Side A or Side B walls or on the guard elements $(X / d<3)$ in the first passage. The height, $(\mathrm{e} / \mathrm{d}=0.1)$, shape (circular) and streamwise spacing or pitch $(\mathrm{P} / \mathrm{e}=10)$ of the trips are typical of the trips cast on the coolant passage walls of turbine blades.

Testing was conducted with air at dimensionless flow conditions typical of advanced gas turbine designs in the Rotating Heat Transfer Laboratory at United Technologies Research Center. The required dimensionless rotation numbers were obtained with rotation rates of 875 RPM or less by operating the model at a pressure of approximately 10 atmospheres. The model inlet air temperature was typically $27 \mathrm{C}(80 \mathrm{~F})$ and the copper elements were held at 49C, 71C, 93C and 116C 1120F, $160 \mathrm{~F}, 200 \mathrm{~F}$ and $240 \mathrm{~F}$ ) for coolant-to-wall temperature differences of $22 \mathrm{C}, 44 \mathrm{C}, 67 \mathrm{C}$ and $89 \mathrm{C}(40 \mathrm{~F}, 80 \mathrm{~F}, 120 \mathrm{~F}$ and $160 \mathrm{~F})$, respectively. Temperatures of the copper elements were measured with two chromel-alumel thermocouples inserted in drilled holes in each element. Heat transfer coefficients were determined by performing an energy balance on each copper element to obtain the convective heat flux and the local coolant bulk temperature. The heat transfer coefficients were based on the projected area rather than the total heat transfer surface area due to trip geometry. The total heat transfer surface area for the test surfaces with trip strips was 1.15 times the projected area. See Wagner et al. (1991a) for additional information about the data reduction procedure.

Nusselt numbers and Reynolds numbers were calculated for each element. The fluid properties in the Nusselt and Reynolds numbers were evaluated at the film temperature. i.e., $T_{1}=\left(T_{w}\right.$ $\left.+T_{b}\right) / 2$. All of the heat transfer results presented herein have been normalized with a correlation for fully-developed, turbulent flow in a smooth tube. The constant heat flux Colburn ecpuation, adjusted for constant wall temperature. was used to obtain the Nusselt number for fully cleveloned. turbulent flow in a smooth tube (Kays and Perkins (1973)). The resulting ecpuation for the constant wall temperature condition with a Prandtl number equal to 0.72 is as follows.

$$
\mathrm{Nu} \mathrm{u}_{\infty}=0.0176 \mathrm{Re}^{0.8}
$$

An uncertainty analysis of the data reduction equations using the methods of Kline and McClintock (1953) showed that approximately $3 / 4$ of the uncertainty in calculating heat transfer coefficient was due to the measurement of temperatures in the model. The uncertainty of the heat transfer coefficient is influenced mainly by the wall-to-coolant temperature difference and the net heat flux from each element. Uncertainty in the heat transfer coefficient increases when either the temperature difference or the net heat flux decreases. For increasing $x / d$, the uncertainty increases because the wall-to-coolant temperature difference decreases. For low heat fluxes (i.e. low Reynolds numbers and on leading surfaces with rotation), the uncertainty in the heat transfer also increased. Estimates of the error in calculating heat transfer coefficient typically varied from approximately \pm 6 percent at the inlet to \pm 30 percent at the exit of the heat transfer moclel for the baseline stationary test conditions. The uncertainty in the lowest heat transfer coefficient on the leading side of the third passage with rolation is estimated to be $\mathbf{4 0}$ percent, primarily due to the uncertainty in the calculated bulk temperature. Although the uncertainty analysis was useful in quantifying the maximum possible uncertainty in calculating the heat transfer coefficient, multiple experiments at the same test condition were repeatable to within ranges smaller than those suggested by the analysis.

\section{RESULTS}

Foreword. Heat transfer in stationary experiments with augmentation devices on the passage walls is primarily a function of the Reynolds number (a flow parameter), the streamwise distance from the inlet, $X / \mathrm{d}$ (a geometric parameter), and the geometry of the augnentation device. However, when rotation is applied, the heat transfer is also strongly influenced by the coupled effects of Coriolis and buoyancy and becomes asymmetric around the passage. An analysis of the equations of motion by Suo (1980, i.e. Appendix 10.1 of Hajek et al. 1991), similar to that of Guidez (1989). showed that the basic dimensionless fluid dynamic parameters governing the flow in a radial coolant passage were the Reynolds number. the rotation number, Ro, the fluid density ratio. $\Delta \rho / \rho$, and the geometric parameter. $\mathrm{R} / \mathrm{d}$. An alternate analysis of the equations of motion produces the rotational Reynolds number, $J=\Omega t^{2} / \nu$ as one of the governing parameters. Note also that Ro equals J/Re. Note that the rotation number, Ro, is the reciprocal of the Rossby number, $V / \Omega d$, and governs the formation of cross-stream secondary flow due to Coriolis forces. The rotation number, Ro, the fluid density ratio. $\Delta \rho / \rho$, and the genmetric narameter. $R / d$, appear in the governing equation as a buoyancy parameter. This buoyancy parameter, $(\Delta \rho / \rho)(R / d)(\Omega d / V)^{2}$. is similar to $\mathrm{Gr} / \operatorname{Re}^{2}$ for stationary heat transfer. The difference between our rotational buoyancy parameter and the stationary $\mathrm{Gr} / \operatorname{Re}^{2}$ is that $\Delta \rho / \rho=\left(T_{w}\right.$ $\left.-T_{1}\right) / T_{w}$ rather than $\beta \Delta T=\left(T_{w}-T_{11}\right) / T_{1}$. The difference between the parameters decreases as $T_{w}$ approaches $T_{1}$. Thus, with rotation, the heat transfer in the first passage is a function of three geometric parameters (surface roughness geometry, $X / d$ and surface orientation relative to the direction of rotation) and three flow parameters (Reynolds number. rotation number and the buoyancy parameter). The heat transfer in the turns and other passages are functions of the aforementioned parameters and the serpentine geometry.

Due to the vector nature of the equations of motion. the combinations of buoyancy forces and the flow direction are expected to have a significant effect on the coolant flow and heat transfer (e.g. Eckert et al., 1953). In the parallel flow case, the flow is radially inward, coincident with buoyancy driven flow for heated walls. For the counter-flow case where the flow is radially outward. the flow direction is opposite to the direction of the buoyancy driven flow. Flow direction (i.e. radially inward or outward) and a fixed radially outward directed force field, created by the rotating reference frame, establish the potential for parallel and counter flow situations.

The nomenclature used in the text for low and high pressure surfaces is consistent with the leading to trailing side, Coriolis-generated, pressure gradients due to the secondary flows. In general, high pressure surfaces have normal components of flow towards the surface while low pressure surfaces have normal components of flow away from the surface. Therefore, trailing surfaces in the first passage with outward flow are on the high pressure side of the passage. Similarly, leading surfaces in the second passage with inward flow are on the high pressure side. For turbine airfoils, the leading surfaces of the coolant passage are adjacent to the suction side of the airfoil and the trailing surfaces of the coolant passage are adjacent to the pressure side of the airfoil.

The format of this paper is to shnw the effects of each of the primary variables $(\mathrm{X} / \mathrm{d}$, rotation number. density ratio) on the heat transfer about a baseline flow conclition to develop an understanding of the cause/effect relationships. At the same time, 
the results for the skewed trips will be compared with results from smooth walls and walls with normal trips in the same test section. The entire body of experimental results are then examined to determine the effects of the buoyancy parameter on the heat transfer in selected locations of the coolant passage. A complete set of results for the walls with trips is also available in a NASA contractors report by Johnson et al. (1992).

\section{HEAT TRANSFER RESULTS FOR BASELINE FLOW CONDITIONS}

The baseline experiments in the three instrumented passages had dimensionless flow conditions which consisted of a Reynolds number of 25,000 and an inlet density ratio, $\left(\rho_{1}-\rho_{w}\right) / \rho_{1}=$ $\left(T_{w}-T_{b}\right) / T_{w}$, of 0.13 . The rotating baseline experiments had a rotation number, $\Omega \mathrm{d} / \mathrm{V}$, of 0.24 and a radius ratio at the average model radius, $R / d$, equal 49 . These values were selected because they are in the central region of the operating range of current large aircraft gas turbine engines.

Stationary Baseline Flow Condition. Streamivise variations of Nusselt number for the stationary baseline test with skewed trips are shown in Figure 4. The Nusselt numbers, (a) for fully developed, turbulent flow in a smooth tube with constant wall temperature (Kays \& Perkins - 1973), (b) for the model with smooth walls (Wagner et al. - 1991b) and (c) for the model with normal trips (Wagner et al. - 1991c), are shown for comparison. The heat transfer from the walls with skewed trips (denoted leading and trailing surface) in the first outward straight $(3<\mathrm{X} / \mathrm{d}$ < 14) passage have heat transfer coefficients more than three times the fully-developed, smooth-wall correlation and more than 50 percent greater than that with normal trips. Note that the heat transfer coefficients on the leading and trailing surfaces with the skewed trips do not decrease significantly with $\mathrm{X} / \mathrm{d}$ in the first passage as they did for the model with the smooth walls. Some differences in heat transfer are observed between the leading and trailing surfaces for this stationary baseline condition. The exact cause of the difference is not known but may be due to the staggering of the trips on the two surfaces (Figure 2).

The heat transfer coefficients on the side walls with smooth surfaces were less than those that on the leading and trailing surfaces with trips. However, the heat transfer with either set of trips was 20 to 100 percent greater than with the smooth walls. This increase in heat transfer on the side walls was attributed to increased velocity due to blockage of the trips for $X / \mathrm{d}=4$ and to the increased turbulence level in the coolant passage for $X / d=8$ and 12. Note also that the heat transfer from the test surfaces of Side A (Figure 2) of the skewed trip model increases markedly at $\mathrm{X} / \mathrm{d}=8$ and 12 . This increase was attributed to the secondary flow, from the center of the conlant passage. with a colcler temperature toward the sidewall with element numbers 1 through 4. The secondary flow was caused by the trips skewed at $45 \mathrm{lleg}$ to the flow direction. The heat transfer coefficients on the trip model with skewed trips are 10 to $\mathbf{3 0}$ percent greater than those on the model with normal trips. The model with skewed trips has approximately five percent greater surface area on the leading surface than the model with normal irips. Therefore most of the increase in heat transfer with skewed trips compared to that with normal trips is attributed to the changes in the flow characteristics.

The heat transfer coefficients measured in the remaining two passages (i.e., $20<\mathrm{X} / \mathrm{d}<31$ ) show similar characteristics. The heat transfer characteristics in the second passage are generally similar to those in the first passage with heat transfer on all walls for the model. The large increases in heat transfer on the leading side of the model at $X / d=21$ (streamwise location $G$ ) and at $\mathrm{X} / \mathrm{d}=38$ (streamwise location $\mathrm{L}$ ) was attributed to the convection interaction of the secondary flow patterns in the first channel through the first $180 \mathrm{deg}$ turn and the concentration of streamwise vorticity adjacent to the leading surface.

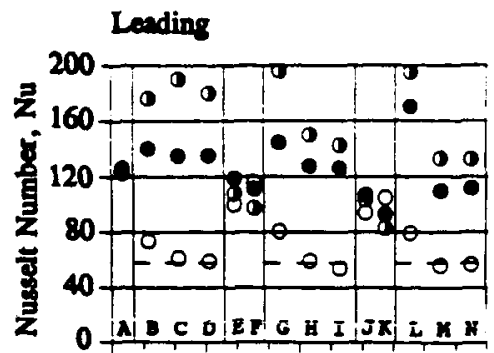

\section{Trailing}
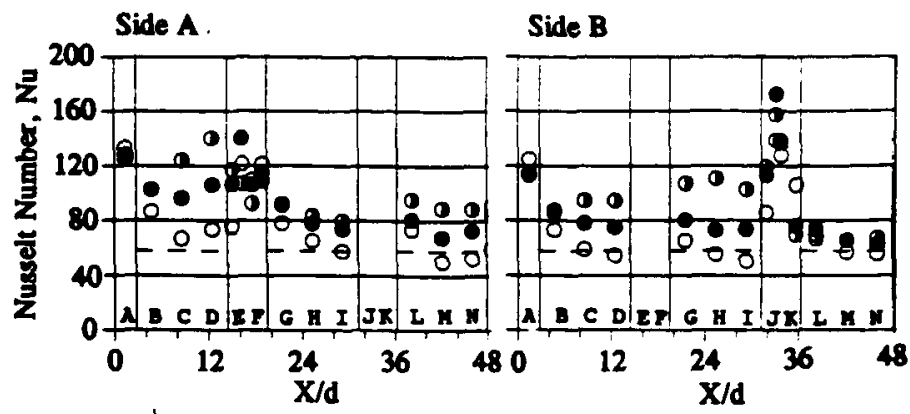

Fig. 4 Effect of Trip Configuration on Heat Transfer for Stationary Baseline Flow Conditions; $\Omega=0 \mathrm{rpm}, \operatorname{Re}=25000, \mathrm{R} / \mathrm{d}=49$, $\alpha=0,(\Delta \rho / \rho)_{\text {in }}=0.13,0$ - smooth wall, - normal trips, - - skewed trips; - - - smooth wall correlation for $\mathrm{Nu}_{\infty}$, leading and trailing notation for $\Omega>0$.

The heat transfer in the turn regions was generally the same for the present experiment with skewed trips. compared to the previous smooth wall and normal trip experiments. The modest changes on the leading and trailing surfaces of the turn sections are attributed in part to the differences in the velocity profiles expected at the entrance to the lurn regions. For the smooth wall flow condition, the velocities are expected to be high in the corners of the duct (e.g. Schlicting, 1968). For flow over normal trips, the velocity can be expected to be peaked in the center of the channel due to the large momentum losses at each trip. The changes in heat transfer on the sides (outside walls of turn sections) attest to the complexity of the flow structure in the turns and is not yet explained.

Rotating Baseline Flow Condition. The streamwise distributions of the Nusselt Number for the Rotating Baseline Flow Condition are presented in Figure 5. Also shown are the results for the heat transfer model with smooth walls and with normal trips and the smooth wall correlation for Nuso. The heat transfer characteristics for the models with trips and rotation are similar to those for the model with smoother walls. That is, in the first passage with flow outward. the heat transfer increases on the trailing side and decreases on the leading side. In addition, in the straight passages, the relative position of the heat transfer coefficients remain the same as for the Stationary Baseline Flow Condition. (The model with the skewed trips has the highest heat transfer coefficients and the model with the smooth walls has the lowest heat transfer coefficients on the leading and trailing sides and on most of the side wall heat transfer surfaces.) However, the ratio of the heat transfer coefficients at each streamwise location varies. At some locations, the heat transfer with the skewed trips are only 5 percent greater than those with normal trips; increases commensurate with the increases in the surface area. (Recall that the heat transfer coefficients are based on projected surface area.)

The largest difference between the heat transfer from the models with skewed and normal trips occurs on the trailing surfaces in the second passage streamwise locations $\mathrm{G}, \mathrm{H}$ and J or $19<X / d<31$. In this region. the heat transfer with the normal trips is closer to the smooth wall value than that with the skewed 


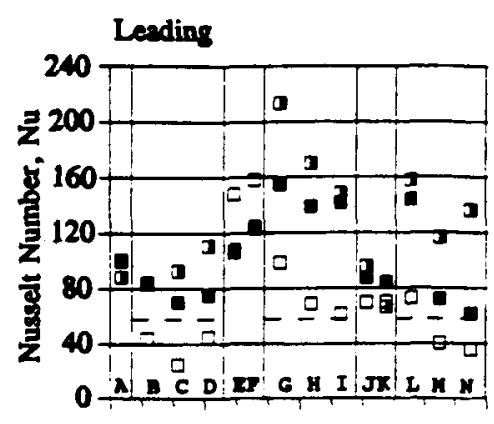

Trailing

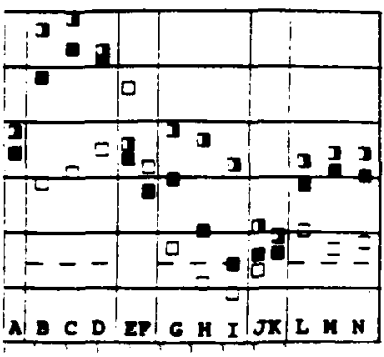

Side A

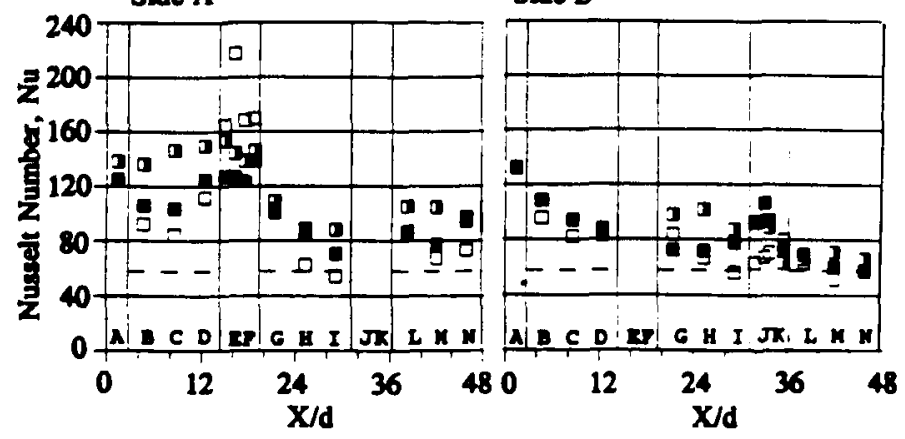

Fig. 5 Effect of Trip Configuration on Heat Transfer for Rotating Baseline Flow Conditions; $\Omega=550 \mathrm{rpm}, \mathrm{Re}=25000$. R/d $=49$, $\alpha=0,(\angle \rho / \rho)_{\text {in }}=0.13, \square-$ smooth wall, $\square-$ normal trips, D- skewed trips, - - - smooth wall correlation for $\mathrm{Nu}_{\infty}$

trips. This behavior was previously (Wagner et al., 1991c) attributed to the formation of buoyancy-driven cells between the normal trips on this trailing surface with flow radially inward. The authors' hypothesis is that the secondary flow produced by the skewed trips precludes such a radially recirculinting flow and the accompanying lower heat transfer coefficients. This model is compatible with the results for calculated flows in circular ducts with square trips (Taylor et al. 1991).

The increase in heat transfer from the models with the trips in the second and third passages was generally less than that obtained in the first outward straight section. This general reduction in heat transfer was attributed primarily to the development of well mixed flow in the coolant passages downstream of the turns and, possibly, the increased uncertainty in the bulk temperature at these downstream locations. (The increased heat transfer compared to the smooth wall model causes the difference between bulk temperalure and the wall temperature to decrease and hence the uncertainty of the heat transfer coefficient determined to increase.)

The heat transfer in the turn regions with rotation is also complex. For the first turn at the model tip (outside radius, E and $F$ ), the heat transfer coefficients with the smooth wall model are the highest on all three surfaces. For the second turn at the model root (inside radius: $J$ and $K$ ), the heat transfer with the smooth model is the lowest. These effects are attributed to the complex flows produced during the convection of secondary flow patterns produced in the straight passage sections upstream of each turn by each of the three types of wall surfaces (smooth, normal trips, skewed trips). Additional analytical effort will be required to delineate the causes for these effects.

\section{HEAT TRANSFER RESULTS FOR VARIATION OF PARAMETERS ABOUT BASELINE FLOW CONDITIONS}

\section{Effect of Rotation}

The rotation number, $\Omega \mathrm{d} / \mathrm{V}$, was varied from 0 to 0.35 for this series of flow conditions. The Reynolds number, inlet density
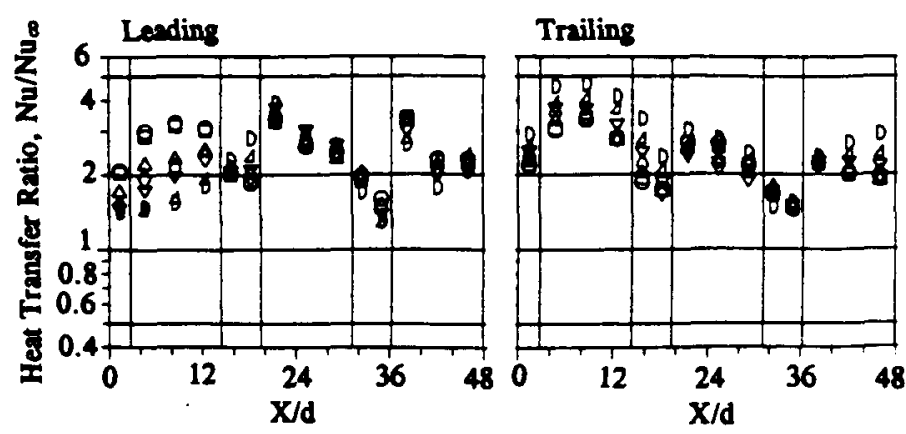

Fig. 6 Effect of Roution Number on Heat Transfer Ratio; Re $=25000$, $R / d=49, \alpha=0,(\Delta \rho / \rho)_{\text {in }}=0.13$, Rotation Nos. $0-0.00$, $\square-0.006, \Delta-0.06, \bigcirc-0.12, \nabla-0.18, \Delta-0.23$, $D-0.34$.

ratio and radius ratio were held constant at the nominal values of $25,000,0.13$ and 49 , respectively. The streamwise distribution of the heat transfer ratios are presented in Figure 6.

The heat transfer ratios vary significantly, i.e. a factor of 2 , on the leading surface. The decrease in heat transfer coefficient due to rotation on the leacting surface of the first passage is approximately the same as previously shown for the models with smooth walls or with normal trips. That is. the heat transfer decreases to approximately one-half the stationary value for $R o=0.24$. The heat transfer in the trailing segments of the first passage increased 30 to 40 percent when the rotation number was increased from 0 to 0.34 .

The effects of rotation are markedly less in the second and third passages. This lack of large variation is attributed to (1) the secondary flow patterns induced by the skewed trip configurations and (2) the effects of the conservation of vorticity through turn reginns on the heat iransfer in the second and third passage. The heat transfer from each of the leacling and trailing segments in the second passage, $19<\mathrm{X} / \mathrm{d}<31$. with flow radially inward is generally within 20 percent of the respective values for $\Omega=0$. The heat transfer from the trailing segments in the third passage with flow radially outward. $36<\mathrm{X} / \mathrm{d}<48$. does increase as much as 50 percent of their respective values for $\Omega=0$. Although these effects were previously recognized, their relative importance regarding the heat transfer was difficult to estimate. The current (e.g., Prakash and Zerkle. 1991) analyses of flows in complex rotating coolant passages are providing insight into the flow and heat transfer characteristics of turbine blade internal cooling.

\section{Effect of Density Ratio}

The inlet density ratio, $(\Delta \rho / \rho)_{i}$. was varied from 0.07 to 0.22 for this series of flow conditions. The Reynolds number. rotation number and radius ratio were held constant at the baseline values of $25.000,0.24$ and 49 . respectively. Heat transfer was obtained at a fixed rotation number and, therefore, conclusions can be obtained regarding the effects of buoyancy for flow conditions near the rotating baseline flow conditions.

Increasing the inlet density ratio (i.e.. the wall-to-coolant temperature difference) from 0.07 to 0.22 causes the heat transfer ratio in the first passage of the model with skewed trips to increase on the trailing surfaces by as much as 25 percent and on the leading surfaces by as much as 20 percent (Figure 7). The exception to the general increase in heat transfer with increasing density ratio occurred near the inlet of the first passage on the leading side, where the heat iransfer ratio is relatively unaffected by varying density ratio. In the second passage, with flow radially inward on the low pressure (trailing edge) side, heat transfer increased as much as 60 percent with increases in the temperature difference. (Larger effects of density ratio were obtained for a rotation number of 0.35 .) 

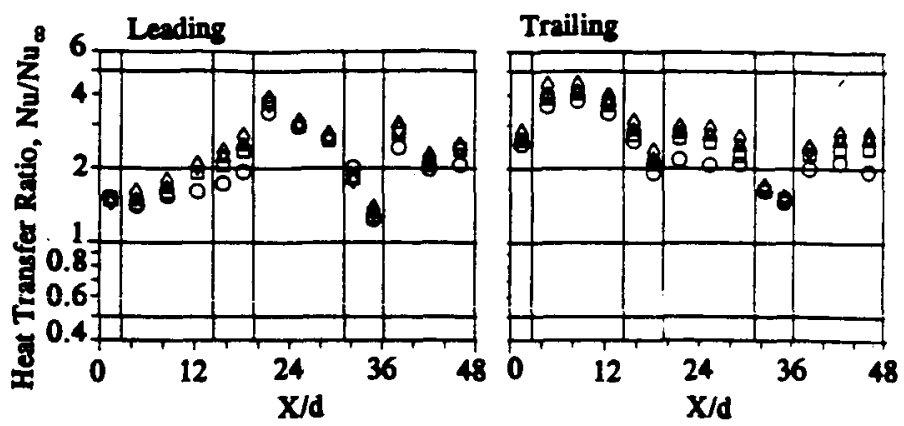

Fig. 7 Effect of Density Ratio on Heat Transfer Ratio; Re $=25000$, $R / d=49, \alpha=0, R_{0}=0.24,(\Delta \rho / \rho)_{\text {in }}$ value $0-0.07$, $\square \cdot 0.12, \Delta-0.18,0-0.23$.

The increase in the heat transfer ratio in the third passage with flow radially outward was also as much as 60 percent as the inlet density was increased. In the third passage, the effects of density ratio on the heat transfer from the leading and trailing surfaces are larger for the model with skewed trips than were measured for the model with normal trips for $\mathrm{Ro}=0.24$.

\section{Effects of Reynolds Number}

The streamwise variation of heat transfer ratio, $\mathrm{Nu} / \mathrm{Nu}_{\infty}$, is presented in Figure 8 for Reynolds numbers from 12,500 to 75,000 , a fixed rotation number, Ro $=0.12$, and a fixed inlet density ratio, $\Delta \rho / \rho_{\text {inlel }}=0.13$. The heat transfer ratios for Re $=50,000$ and 75,000 at all locations are well correlated by use of the Kays and Perkins correlation, i.e. with the Nusselt number proportional to Reynolds number to the 0.8 power. The variations between the heat transfer ratios for Reynolds number equal 25,000 and those for 50,000 and 75,000 are generally less than 10 percent. The variation for Reynolds numbers of 12,500 is greater, especially in regions with the highest heat transfer coefficients.

The conclusion from these rotating and stationary experiments was that the relationship for fully developed flow in a square duct with smooth walls, $\mathrm{Nu}_{\infty}=0.0176 \mathrm{Re}^{0.8}$, would be adequate for scaling the effects of Reynolds number on the heat transfer ratio.

\section{Effects of Passage Orientation}

Heat transfer experiments were conducted with the piane of the coolant passages rotated 45 degrees to the axis of rotation $(\alpha=45 \mathrm{deg})$ for the model with skewed trips. See Figure $3 b$ for the model orientation. The effect of model orientation on the streamwise distribution of the heat transfer ratio for the four surfaces is presented in Figure 9 . The heat transfer ratios for the Rotating Baseline Flow Conditions are presented for $\alpha=0$ and 45 degrees. In the first coolant passage, rotation of the model from $\alpha=0$ to $\alpha=45$ degrees caused the heat transfer ratio to decrease on both side walls and the trailing side and to increase or remain the same on the leading side. In the second passage small decreases in the heat transfer ratio occurred on all four sides of the coolant passage. The conclusion from this comparison is that the heat transfer ratios can increase or decrease 20 to 30 percent with the coolant passage orientation up to 45 degrees from the $\alpha=0$ orientation for this trip strip geometry and coolant passage aspect ratio.

\section{CORRELATING PARAMETERS}

In this section, the heat transfer ratios will be presented for specific locations on the leading and trailing surfaces in the three passages. The heat transfer ratios will be presented as

1) the variation of local rotation number with
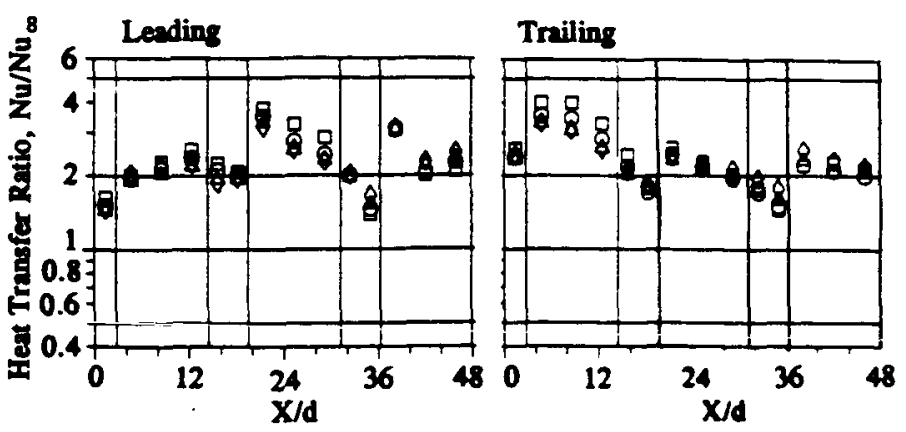

Fig. 8 Effect of Reynolds Number on Heat Transfer Raio for a Rotation Number of $0.12 ; R / d=49, \alpha=0,(4 \rho / \rho)_{\text {in }}=0.13, R_{0}=0.12$, Reynolds Nos. $\square-12500,0-25000, \triangle-50000.0$. 75000 .
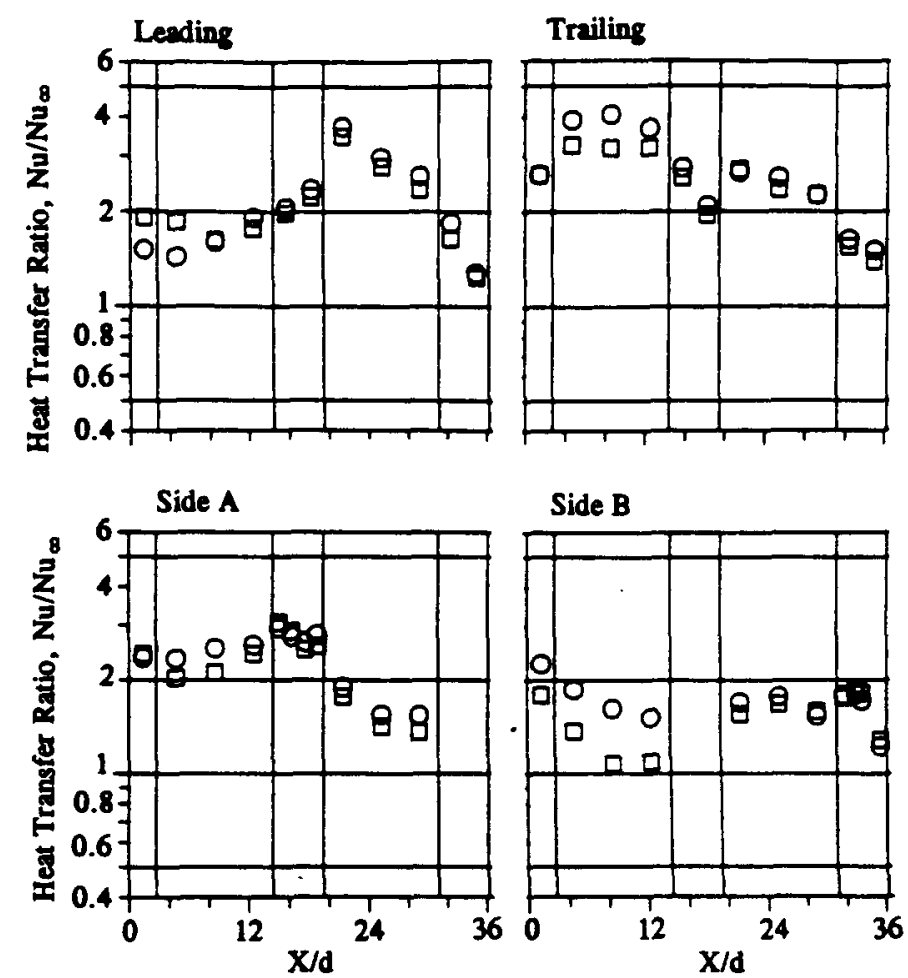

Side B

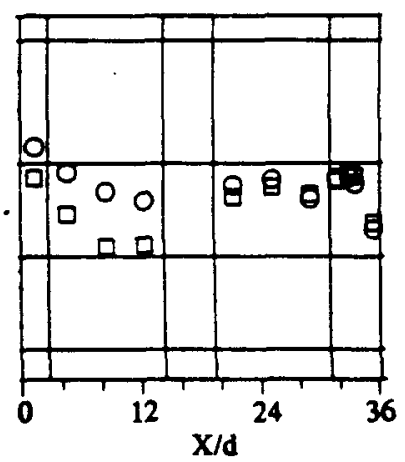

Fig. 9 Effect of Model Orientation (Alpha) on Heat Transfer Ratio of Skewed Trips; $\operatorname{Re}=25000, R / d=49,(\alpha \rho / \rho)_{\text {in }}=0.13$, $R_{0}=0.23$, alpha values $\bigcirc-0 \mathrm{deg}, \square-45 \mathrm{deg}$.

each inlet density ratio noted, and

2) the variation of the local buoyancy parameter with each rotation rate and inlet density ratio noted.

The results from the models with smooth walls and with normal trips are also presented for comparison. With these two presentations, the similarities and differences of the heat transfer characteristics from the three models with normal and skewed trips and with smooth walls can be identified and discussed.

\section{Variation with Rotation Number}

The heat transfer ratios for the downstream leading and trailing surfaces in the three straight passages are presented in Figure 10. The test surface identification number (Figures 2 and 3). the streamwise lncation and the $X / d, X^{\prime} / d$ or $X^{\prime \prime} / d$ ratio from 
Low Pressure

Firat Pasange Flow Outward $X / d=12.4$

Second Pasenge Flow Inward $X^{\prime} / d=9.7$

Third Passage Flow Outward $X^{\prime \prime} / d=9.7$
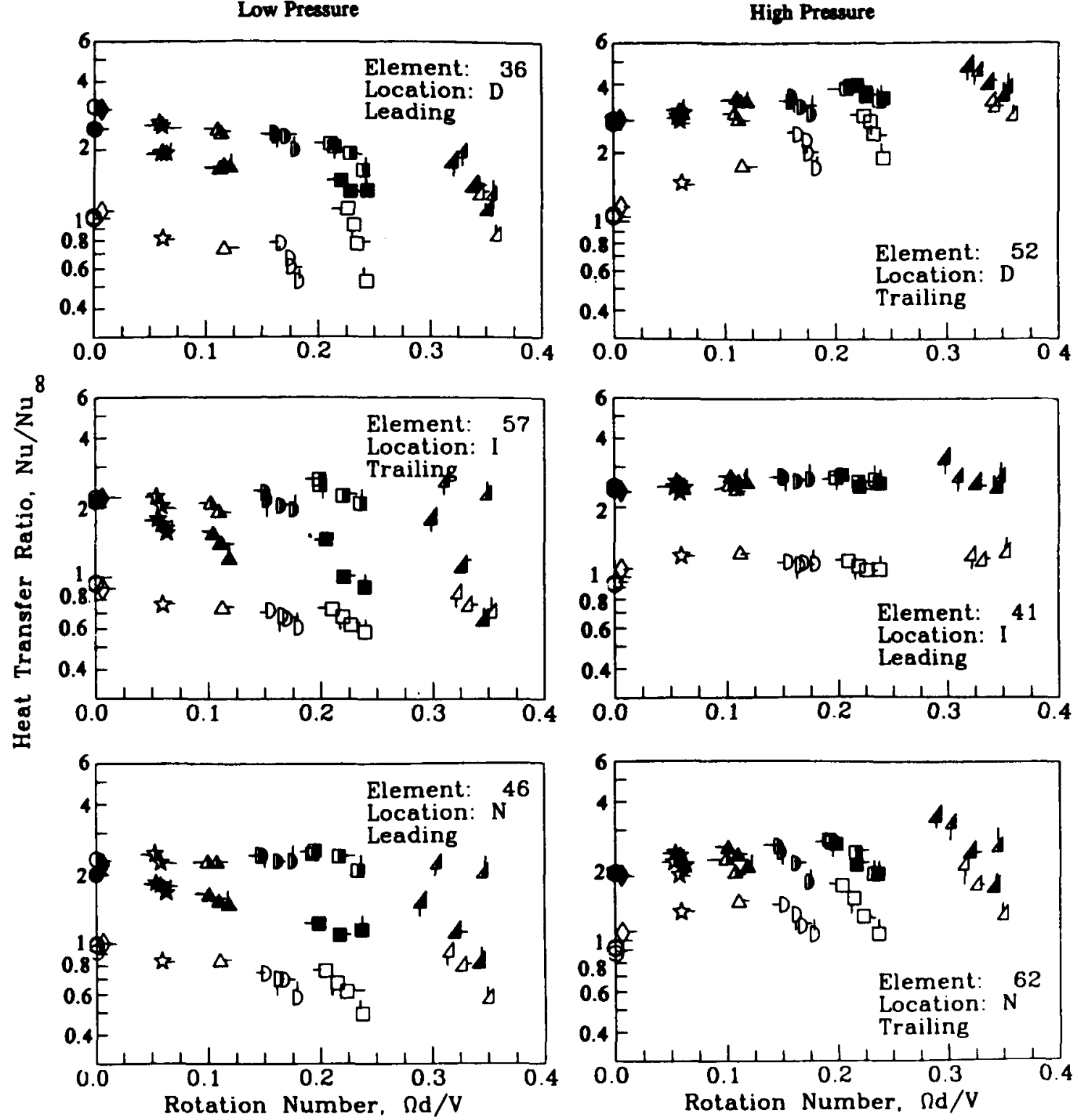

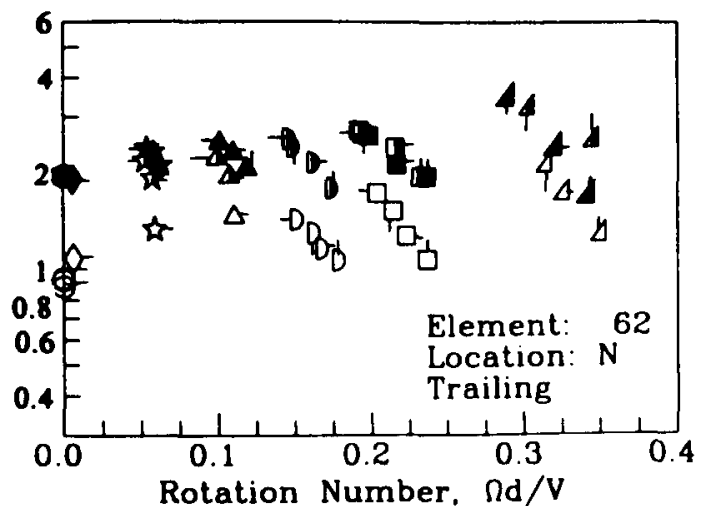

Fig. 10 Effect of Rotation Number on Heat Transfer Ratios in the First, Second and Third Passages; Re $=25000, R / d=49$, open symbols - smooth wall data, solid symbols - normal trip data, half solid symbols - skewod trip data.

the start of each straight section are also shown on each panel of the figure.

High Pressure Surfaces. The trailing surfaces of the first and third passages and the leading surface of the second passage are denoted as the high pressure surfaces. In the first and third passages of both models with trips, the heat transfer coefficients increase with increasing rotation number at approximately half the slope as these for the model with smooth walls. The increases in heat transfer ratios, due to rotation, are as much as 75 percent compared to the heat transfer ratios for the same models with trips and no rotation. Also, the heat transfer ratios in the second passage with flow radially inward are essentially independent of rotation. Note that the heat transfer from the models with trips is essentially independent of inlet density for Ro $\leq 0.24$ in the first two passages. The uncertainty in the heat Iransfer measurements in the third channel increases due to small bulk to wall temperature differences for the low inlet density ratios.
However, the results for the third passages with trips show characteristics similar to those for the third passage with smooth walls.

Low Pressure Surfaces. The heat transfer from the low pressure surfaces is more complex than that from the high pressure surfaces. The heat transfer ratio in the first passage with both the normal and skewed trips decreases with increasing rotation number at the downstream location for the range of values tested, i.e. $\Omega \mathrm{d} / \mathrm{V}<0.36$. At the larger values of $\Omega \mathrm{d} / \mathrm{V}$, $0.24-0.36$, the heat transfer ratio increases with increases in the density ratio, similar to the results obtained for the trailing surface of the first passage.

The effects of inlet density ratio on the heat transfer ratio in the second passage are of order 10 percent for the model with skewed trips and with flow radially inward. Note that large variations of order 300 percent were obtained for the model with normal trips in this passage for $\Omega \mathrm{d} / \mathrm{V}=0.34$. Note also that the 
Low Pressure

\section{Firn Pasage Flow Outwend $X / d=12.4$}

Second Pasarge Flow Inward $X / d=9.7$

Third Pasange Flow Outward $X^{* \prime} / d=9.7$

苞

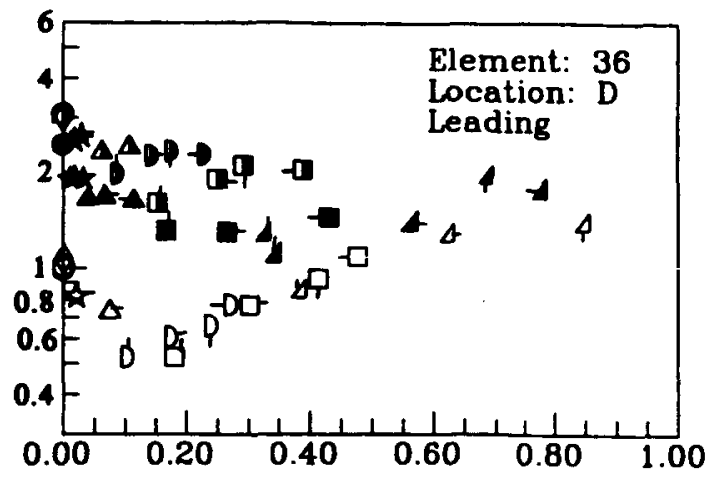

High Pressure
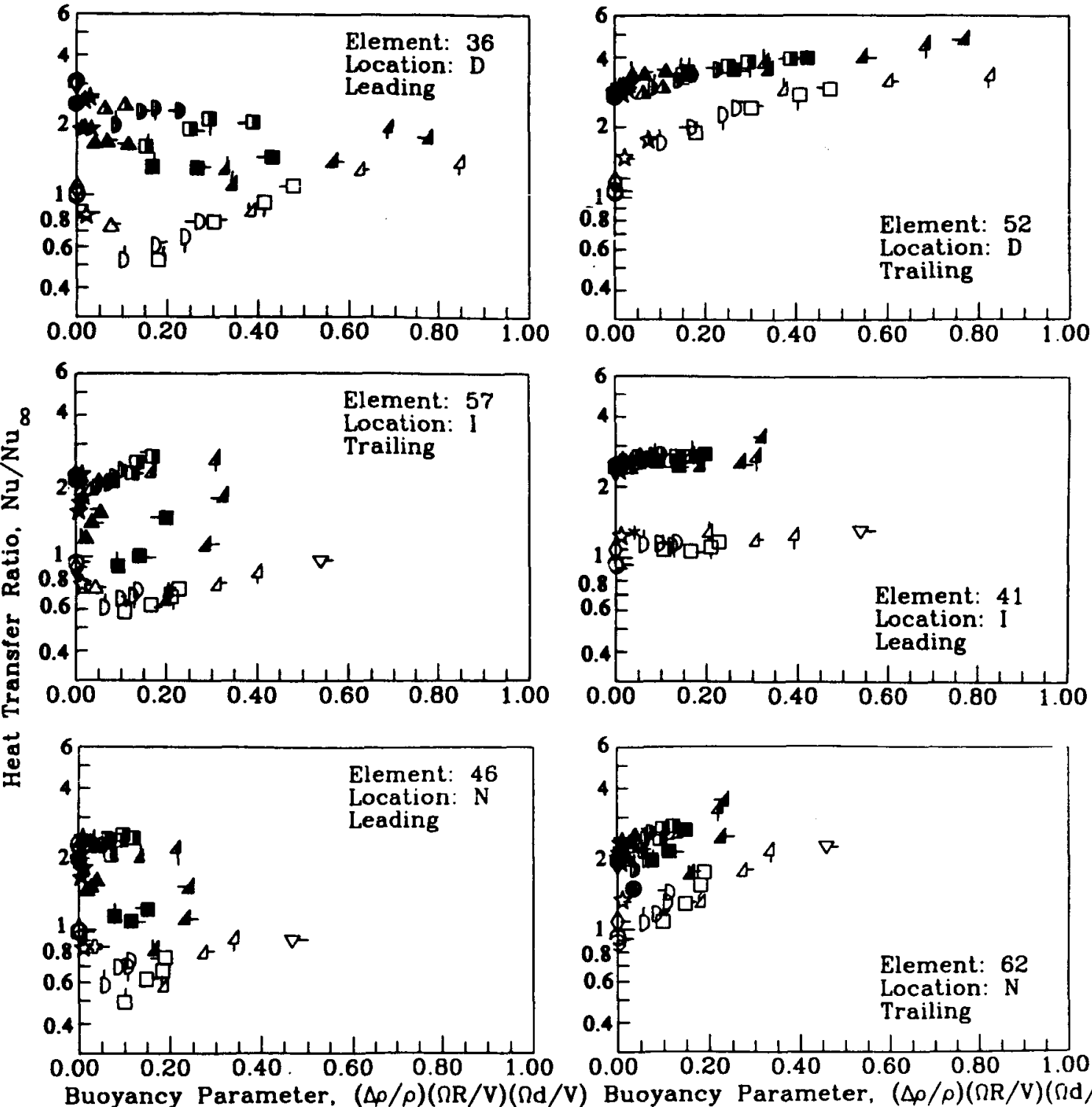

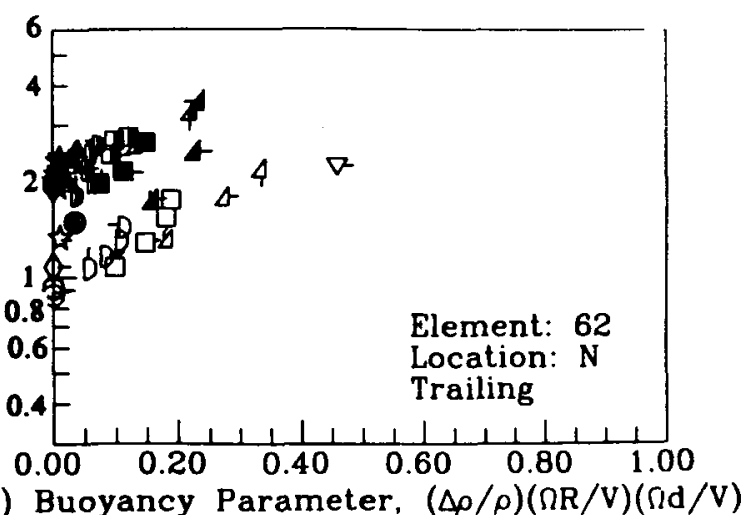

Fig. 11 Effect of Buoyancy Parameter on Heat Transfer Ratios in the First, Second and Third Passages; Re $=25000, R / d=49$. open symbols - smooth wall data, solid symbols - normal trip data, half solid symbols - skewed trip data.

Symbol Flags for Figs. 10 and 11

\begin{tabular}{|c|ccc|}
\hline Symbol & $\left.\Delta \mathrm{T}_{\text {in }}{ }^{\circ} \mathrm{C}\right)$ & $\left.\Delta \mathrm{T}_{\text {in }}{ }^{\circ} \mathrm{F}\right)$ & $(\Delta \rho / \rho)_{\text {in }}$ \\
\hline$\delta$ & 22.4 & 40 & 0.07 \\
$O-$ & 44.7 & 80 & 0.13 \\
$Q$ & 67.1 & 120 & 0.18 \\
- & 89.1 & 160 & 0.22 \\
\hline
\end{tabular}

local density ratios in the second passage are about half of the inlet values.

The heat transfer characteristics of the third passage are more similar to those of the second passage than to those of the first passage for each moclel. The model with skewed trips showed less decrease in heat transfer with increasing rotation than the models with the normal trips or the smooth walls.
The more complicated heat transfer distributions on the low pressure surfaces of the coolant passages are attributed to 1) the combination of buoyancy forces and the stabilization of the near-wall flow for low values of the rotation number, 2) the developing, Coriolis driven secondary flow cells and 3). the increases in flow reattachment lengths after trips for the larger values of the rotation number. It is postulated that the relatively small effects from variations in density ratio near the inlet of the second passage and the large effects near the end of the second passage are due to the development of the near-wall thermal layers (i.e. thickening for the normal trip model compared to thinning for the smooth wall model). Near the inlet of the second passage, the thermal layers are postulated to be thin because of the strong secondary flows in the first turn region. With increasing $\mathrm{X} / \mathrm{d}$. the turn dominated secondary flows diminish and the counteracting effects of buoyancy and the Coriolis generated secondary flow increase. 


\section{Variations with Buoyancy Parameter}

The buoyancy parameter, $(\Delta \rho / \rho)(\Omega R / V)(\Omega d / V)$, has been effective for the correlation of heat transfer results from the model with smooth walls (Wagner et al., 1991a \& 1991b). The best correlation was made for streamwise locations of $\mathrm{X} / \mathrm{d}=$ 12 and for values of the buoyancy parameter greater than 0.20 . In this section, the heat transfer ratios from the leading and trailing surfaces in the three passages are presented and compared with results from the models with smooth walls and with normal trips.

The variations of the local heat transfer ratio with the buoyancy parameter in the first passage with flow outward are shown in Figure 11. The heat transfer from the trailing surfaces is correlated better with the buoyancy parameter than with the rotation number (Figure 10) or the inlet density ratio (not shown). Note that the heat transfer ratios of test surface 52 for both the skewed and normal trips are 25 and 20 percent greater than the heat transfer ratios for the smooth walls and for buoyancy parameters $>0.6$. Recall that the total surface areas for the skewed and normal trips are 15 and 10 percent greater than for the smooth walls, respectively, and that the heat transfer coefficients and hence heat transfer ratios are based on the projected area. The conclusion is that half or more of the increase in heat transfer occurs due to the increased surface area. The increase in local heat transfer coefficient due to trips ( 10 percent) for high rotation numbers and high values of the buoyancy parameter is a small fraction of the 150 to 200 percent increase due to the trips at zero rotation.

The variations of heat transfer ratio with the buoyancy parameter for the leading (low pressure) surfaces in the first passage show several of the same characteristics previously shown for the results from the smooth model. However, for Ro $\leq 0.25$, the heat transfer ratios are correlated better by the rotation number (Figure 10) than by the buoyancy parameter. For test surface 36 and at values of the buoyancy parameters greater than 0.6 . the increase in the heat transfer ratio with skewed trips is as much as 35 percent greater than with the smooth walls. For the same condition with normal Irips. the heat transfer coefficients were only 20 percent greater than with the smooth wall. However, the heat transfer on both surfaces with trips is as much as 50 percent less than the values obtained without rotation!

The variation of the heat transfer ratio with the buoyancy parameter in the second passage with flow radially inward shows markedly different results between the current model and previous model with normal trips. For the current model with skewed trips, the leading surfaces, e.g., element 41 , are well correlated by the buoyancy parameter but have values of the heat transfer ratio which are not more than 10 to 20 percent greater than the value for the stationary model. The trailing surfaces, e.g., element 57 , are reasonably well correlated by the buoyancy parameter. However, the maximum decrease in heat transfer ratio from the stationary ratio is less than $\mathbf{3 0}$ percent whereas the smooth wall model had decreases of approximately 40 percent. It should be noted that the decrease in absolute values are greater for the model with skewed trips $\left(0.75 \mathrm{Nu}_{\infty}\right)$ than for the model with smooth walls $\left(0.45 \mathrm{Nu}_{\infty}\right)$.

\section{SUMMARY OF RESULTS AND CONCLUSIONS}

Results from the present experiments with skewed trips in rotating, radial, square coolant passages show that Coriolis forces and buoyancy effects can strongly influence heat transfer. However, the heat transfer coefficients were much less sensitive to buoyancy effects than were those previously measured with normal trips. The maximum effects of buoyancy on surfaces with skewed trips were also less than occurred on smooth surfaces. The author's conclusions from these observations are that skewed trips provide higher heat transfer coefficients and less sensitivity to buoyancy effects and that skewed trips, rather than normal trips, should be employed for rotating coolant passages.

The comparison of results from the present experiments with previous results for models with smooth wall and with normal trips shows that flow and heat transfer in rotating coolant passages can be complex, especially when no single flow mechanism dominates the heat transfer process. The present results were obtained for skewed trips with values of trip streamwise pitch to trip height $(\mathrm{P} / \mathrm{e})=10$ and trip height to coolant passage width $(e / D)=0.1$, typical of those used in coolant passages. For stationary coolant passage, these trip geometries generally produce heat transfer coefficients which are ihree times those obtained with smooth wall passages with fully developed flow. The wide range of heat transfer coefficients obtained with rotation (1.2 to 5.0 times the values for fully developed flow in smooth passages) indicates that it is prudent to have a data base available for the design of specific coolant passages used in rotating turbine blades.

Following is a summary of comments regarding the importance of each of the parameters previously identified.

- Reynolds Number - The heat transfer ratios for stationary and rotating conditions are reasonably well correlated by a $\mathrm{Nu}-\mathrm{Re}^{0.8}$ relationship. For low Reynolds numbers, i.e. $\operatorname{Re}-12,500$, the exponent may be less.

- Rotation Number - The rotation number correlates the heat transfer ratios better for more surface locations and flow conditions when the heat transfer surfaces have skewed ribs than it did for the model with smooth walls. The decrease in heat transfer ratio from the stationary value on the low pressure sicle of the first coolant passage is well correlated by the rotation number for $R o \leq 0.24$. The percentage decrease on the low pressure sicle of the first coolant passage was essentially independent of the three wall surface geometries.

- Density Ratio and Buovancy Parameter - For these tests with a constant value of $R / d$, the density ratio. the rotation number and the Reynolds numbers are independent flow parameters and the buoyancy is determined by the variations of the density ratio and the rotation number, i.e. $(\Delta \rho / \rho)(\Omega d / V)^{2}(R / d)$. The density ratio is a lesser factor in heat transfer when the flow in the coolant passage is well mixed. For most flow situations with the skewed trips, the flow is apparently well mixed and the effects of density ratio are minimal for Ro $<0.25$.

- Streamwise Location - The heat transfer with skewed trips does not vary as much with streamwise location compared to the smooth wall model. The large decrease in heat transfer with increasing distance from the inlet measured in the model with smooth walls does not occur with the trips. The exception occurs for flow downstream of turns with the skewed trips where the upstream vorticity has been convected to one side of the model and the flow readjusts in the new passage.

- Trip Orientation - The secondary flows produced by the trips can have a large effect on heat transfer. The skewed trips apparently caused secondary flow patterns which dicl not produce strong effects of clensity ratio. The normal trips apparently caused flow patterns which produced strong effects of density' ratio (Wagner el al., 199/c).

- Flow Direction - The effects of flow direction were generally less for the models with trips compared to the model with smooth walls. 


\section{ACKNOWLEDGEMENTS}

The work published in this paper was supported by the NASA/Lewis Research Center under the IIOST Program, Contract No. NAS3-23691 to the Pratt and Whitney Commercial Engine Business/Engineering Division and by the United Technology Corporation's independent research program. The authors gratefully acknowledge the assistance of Ms. S. Orr (UTRC) and Mr. J. Minguy (UTRC) in the performance of this program. The authors are appreciative of the support and guidance by the HOST management team at NASA/Lewis Research Center and by their colleagues at P\&W and UTRC.

\section{REFERENCES}

Boyle, R. J., 1984, Heat Transfer in Serpentine Passages with Turbulence Promoters. ASME Preprint 84-HT-24. Also issued as NASA Technical Memorandun 83614.

Eckert. E. R. G., Diaguila, A. J. and Curren, A. N., 1953, "Experiments on Mixed-, Free- and Forced-Convective Heat Transfer Connected with Turbulent Flow Through a Short Tube," NACA Technical Note 2974.

Guidez, J., 1989, "Study of the Convective Heat Transfer in Rotating Coolant Channel," ASME Journal of Turbomachinery, Vol. 111, pp. 43-50. Also ASME Preprint 88-GT-33 presented in Amsterdam, The Netherlands.

Hajek, T. J., Wagner, J. H., Johnson, B. V., Higgens, A. W. and Steuber, G. D., 1991, "Effects of Rotation on Coolant Passage Heat Transfer: Volume I - Coolant Passages with Smooth Walls," NASA Contractors Report 4396, Vol. I.

Han, J. C., Park, J. S. and Ihrahim, M. Y., 1986, "Measurement of Heat Transfer and Pressure Drop in Rectangular Channels With Turbulence Promoters," NASA Contractor Report 4015.

Hart, J. E., 1971, "Instability and Secondary Motion in a Rotating Channel Flow," J. Fluid Mech., Vol. 45, Part 2, pp. $341-351$.

Iskakov, K. M. and Trushin, V. A., 1983. "Influence of Rotation on Heat Transfer in a Turbine-Blade Radial Slot Channel," Izvestiya VUZ. Aviatsionnaya Tekhnika, Vol. 26, No. 1, pp. 97-99.

Johnson, B. V., 1978, "Heat Transfer Experiments in Rotating Raclial Passages with Supercritical Water." Gas Turhine Heat Transfer, HTD-125 (Bound proceedings from 1978 ASME Winter Annual Meeting).

Johnson, B. V., Wagner, J. H. and Steuber, G. D., 1992 , "Effect of Rotation on Coolant Passage Heat Transfer: Volume II - Coolant Passages with Trips Normal and Skew to the Flow." NASA Contractors Report 4396, Vol. II.

Johnston, J. P., Halleen, R. M. and Lezius, D. K., 1972, "Effects of Spanwise Rotation on the Structure of Two-Dimensional Fully Developed Turbulent Channel Flow," J. Fluid Mech., Vol. 56, Part 3, pp. 533-557.

Kays. W. M. and Perkins. H. C., 1973, "Forced Convection, Internal Fow in Ducts." From Handbook of Heat Transfer, ed. by Rohsenow, W. M. and Hartnett, J. P., McGraw Hill, pp. 7-28 and 7-33.

Kline, S. J. and McClintock, F. A., 1953, "Describing Uncertainties in Single Sample Experiments," Mechanical Engineering, Vol. 75, pp. 3.

Lokai, V. 1. and Gunchenko, E. I., 1979, “Heat Transfer Over the Initial Section of Turbine Blade Cooling Channels Under Conditions of Rotation," Therm. Enging., Vol. 26, pp. 93-95.
Metzger, D. E., Fan. C. S. and Plevich, C. W.. 1988, "Effects of Transverse Rib Roughness on Heat Transfer and Pressure Losses in Rectangular Ducts with Sharp 180 Degree Turns," AlAA Paper 88-0166.

Moore, J., 1967, "Effects of Coriolis on Turbulent Flow in Rotating Rectangular Channels," M.I.T. Gas Turbine Laboratory Report No. 89.

Mori, Y., Fukada, T. and Nakayama, W., 1971, "Convective Heat Transfer in a Rotating Radiai Circular Pipe (2nd Report)," Int. J. Heat Mass Transfer, Vol. 14, pp. 1807-1824.

Morris, W. D. and Ayhan, T., 1979, "Observations on the Influence of Rotation on Heat Transfer in the Coolant Channels of Gas Turbine Rotor Blades," Proc. Instn. Mech. Engrs., Vol. 193, pp. 303-311.

Morris, W., 1981, "Heat Transfer and Fluid Flow in Rotating Coolant Channels," Research Studies Press.

Prakash, C. and Zerkle, R., 1991. "Prediction of Turbulent Flow and Heat Transfer in a Radially Rotating Square Duct", Heat Transfer in Gas Turbine Engines (E. Elovic and H. Martin, eds), ASME HTD Vol. 188 (Bound proceedings from 1991 ASME Winter Annual Meeting).

Rothe, P. H. and Johnston, J. P., 1979. "Free Shear Layer Behavior in Rotating Systems." J. Fluids Enging., Vol. 101, pp. 117-120.

Schlicting, H., 1968, Boundary-Layer Theory, McGraw-Hill Book Company, New York. Gth Fdition. Np. 575

Suo, M., 1980, “Dimensionless Analysis Notes," United Technologies Research Center. Included as "Analysis of Equations of Motion" (Section 10.1), Effects of Rotation on Coolant Passage Heat Transfer: Volume I - Coolant Passages with Smooth Walls, NASA Contractor Report 4396, Vol. I, September, 1991

Taslim, M. E., Bondi, L. A. and Kercher, D. M., 1991b, "An Experimental Investigation of Heat Transfer in an Orthogonally Rotating Chanel Roughened with 45 Deg Criss-Cross Ribs on Two Oposite Walls," ÁSME Journal of 'Turbomachinery, Vol. 113 ,pp. 346-353. (Also ASME Paper 90-GT-332).

Taslim, M. E., Rahman. A. and Spring. S. D, 1991a, "An Experimental Investigation of Heat Transfer Coefficients in a Spanwise Rotating Channel with Two Opposite Rib-Roughened Walls," ASME Journal of Turbomachinery, Vol. 113, No. 1, January 1991, pp. 75-82. Also ASME Paper 89-GT-150.

Taylor, C., Xia, J. Y., Medwell, J. O.. Morris, W. D., 1991, "Numerical Simulation of Three Dimensional Turbulent Flow and Heat Transfer Within a Multi-Ribbed Cylindrical Duct," ASME Paper 91-GT-8, June 1991.

Wagner, J. H., Johnson, B. V. and Hajek, T. J.. 1991a, "Heat Transfer in Rotating Passages with Smooth Walls and Radial Outward Flow," ASME Journal of Turbomachinery, Vol. 113, No. 1, January 1991, pp. 42-51. Also ASME Paper No. 89-GT-272.

Wagner, J. H., Johnson, B. V. and Kopper. F. C., 1991b, "Heat Transfer in Rotating Serpentine Passages with Smooth Walls," ASME Journal of Turhomachinery, Vol. 113, No. 3, July 1991, pp. 321-330. Also ASME Paper 90-GT-331.

Wagner, J. H., Johnson, B. V., Graziani. R. A., and Yeh, F. C., 1991c, "Heat Transfer in Rotating Serpentine Passages with Trips Normal to the Flow." ASME Paper 91-GT-265, June 1991. Also issued as NASA TM 103758.

Wagner, R. E. and Velkoff, H. R., 1972, "Measurements of Secondary Flow's in a Rotating Duct," J. Eng. for Power. Also ASME Paper 72-GT-17. 
Public reporting burden for this collection of information is estimated to average 1 hour per response, including the time for reviewing instructions, searching existing data sources, gathering and maintaining the data needed, and completing and reviewing the collection of information. Send comments regarding this burden estimate or any other aspect of this Davis Highway, Suite 1204, Arlington, VA 22202-4302, and to the Oftice of Management and Budget, Paperwork Reduction Project (0704-0188), Washington, DC 20503.
1. AGENCY USE ONLY (Leave blank) 2. REPORT DATE
1992
3. REPORT TYPE AND DATES COVERED
Technical Memorandum

4. TITLE AND SUBTITLE

Heat Transfer in Rotating Serpentine Passages With Trips Skewed to the Flow 5. FUNDING NUMBERS

WU $-505-62-52$

\section{AUTHOR(S)}

B.V. Johnson, J.H. Wagner, G.D. Steuber, and F.C. Yeh

\section{PERFORMING ORGANIZATION NAME(S) AND ADDRESS(ES)}

National Aeronautics and Space Administration

Lewis Research Center

Cleveland, Ohio 44135-3191
8. PERFORMING ORGANIZATION REPORT NUMBER

E-6908

9. SPONSORING/MONITORING AGENCY NAMES(S) AND ADDRESS(ES)

10. SPONSORING/MONITORING AGENCY REPORT NUMBER

NASA TM- 105581

National Aeronautics and Space Administration

Washington, D.C. 20546-0001

11. SUPPLEMENTARY NOTES

Prepared for the 37th American Society of Mechanical Engineers International Gas Turbine and Acroengine Congress and Exposition, sponsored by the 1992 ASME Turbo Expo-Land, Sea and Air. Cologne, Germany, June 1-4, 1992. B.V. Johnson and J.H. Wagner, United Technologies Research Center, East Hantford, Connecticut , 06108; G.D. Steuber, Pratt \& Whitney, East Hartford, Connecticut, 06108, and F.C. Yeh, NASA Lewis Research Center, Cleveland, Ohio. Responsible person F.C. Yeh, (2 I6) 433-5872.

12a. DISTRIBUTION/AVAILABILITY STATEMENT

12b. DISTRIBUTION CODE

Unclassified - Unlimited

Subject Categories 07 and 34

13. ABSTRACT (Maximum 200 words)

Experiments were conducted to determine the effects of buoyancy and Coriolis forces on heat transfer in turbine blade internal coolant passages. The experiments were conducted with a large scale, multi-pass, heat transfer model with both radially inward and outward flow. Trip strips, skewed at $\mathbf{4 5}$ degrees to the flow direction, were machined on the leading and trailing surfaces of the radial coolant passages. An analysis of the governing flow equations showed that four parameters influence the heat transfer in rotating passages: coolant-to-wall temperature ratio, rotation number, Reynolds number and radius-to-passage hydraulic diameter ratio. The first three of these four parameters were varied over ranges which are typical of advanced gas turbine engine operating conditions. Results were correlated and compared to previous results from similar stationary and rotating models with smooth walls and with trip strips normal to the flow direction. The heat transfer coefficients on surfaces, where the heat transfer decreased with rotation and buoyancy, decreased to as low as 40 percent of the value without rotation. However, the maximum values of the heat transfer coefficients with high rotation were only slightly above the highest levels previously obtained with the smooth wall model. It was concluded that (1) both Coriolis and buoyancy effects must be considered in turbine blade cooling designs with trip strips, (2) the effects of rotation are markedly different depending upon the flow direction and (3) the heat transfer with skewed trip strips is less sensitivity to buoyancy than the heat transfer in models with either smooth walls or normal trips. Therefore, skewed trip strips rather than normal trip strips are recommended and geometryspecific tests will be required for accurate design information.

14. SUBJECT TERMS

Heat transfer; Rotating blade passages; Turbulators

12

12

$\mathrm{AO} 3$

17. SECURITY CLASSIFICATION OF REPORT

Unclassified

\section{SECURITY CLASSIFICATION OF THIS PAGE Unclassified}

19. SECURITY CLASSIFICATION OF ABSTRACT Unclassified 